\title{
ПРОБЛЕМА СООТНОШЕНИЯ ЭМПИРИЧЕСКОГО И ТЕОРЕТИЧЕСКОГО УРОВНЕЙ НАУКИ: МАТЕМАТИЧЕСКОЕ МОДЕЛИРОВАНИЕ В СВЕТЕ ФИЛОСОФСКОЙ РЕФЛЕКСИИ
}

\section{THE PROBLEM OF THE RELATIONSHIP OF EMPIRICAL AND THEORETICAL LEVELS OF SCIENCE: MATHEMATICAL MODELING IN THE LIGHT OF PHILOSOPHICAL REFLEXION}

\section{T. Sheveleva}

Summary: The article presents the history of the formation and philosophical understanding of one of the most frequently used theoretical methods of scientific cognition in recent decades, namely mathematical modeling. (As you know, «direct experiments» in many situations are not always technically feasible and / or morally acceptable). The relevance of this problem is determined by the ongoing debate about, firstly, the metaphysical status of mathematical models, and, secondly, the limits of their applicability.

Keywords: model (imitation, cybernetic), philosophy of mathematics, interaction of philosophy and particular sciences, absolute and relative truth.

\author{
Шевелева Татьяна Анатольевна \\ Аспирант, Омский государственный \\ технический университет \\ tatyana0781@mal.ru
}

Аннотация: В статье представлена история становления и философское осмысление одного из наиболее часто используемых в последние десятилетия теоретических методов научного познания, а именно математического моделирования. (Как известно, «прямые эксперименты» во многих ситуациях не всегда технически осуществимы и/или морально допустимы). Актуальность этой проблемы определяется продолжающимися по сей день дебатами по поводу, во-первых, метафизического статуса математических моделей, и, во-вторых, границ применимости последних. Последовательно решая эти два вопроса - онтологический и гносеологический - в рамках методологии диалектического материализма, мы приходим, с одной стороны, к выводу о принципиальной невозможности создания модели, которая бы сообщила исследователю абсолютную истину о моделируемом объекте (в частности и потому, что на процесс моделирования с необходимостью влияют те или иные теоретические установки). ( другой же стороны, каждая математическая модель, построенная в соответствие с рассмотренными в статье этапами, помогает получить знание, которое можно охарактеризовать в качестве относительной истины.

Ключевые слова: модель (имитационная, кибернетическая), философия математики, взаимодействие философии и частных наук, абсолютная и относительная истина.

\section{Введение}

$\mathrm{B}$ последние десятилетия в научных исследованиях всё большее применение находит математическое моделирование (от латинского «modulus», т. е. «образец», «мера»). Соответствующие модели разрабатываются в различных отраслях науки: информатика, физика, социология, биология, медицина и т.д. Рассмотрим суть этого метода, обратившись как к философской, так и к частнонаучной литературе. В словаре «Общие проблемы философии науки» под редакцией видного отечественного философа науки Н. В. Бряник научное знание делится на два уровня: экспериментальный и теоретический, и, соответственно, выделяются такие виды познавательной деятельности в науке: эмпирическое (непосредственное взаимодействие исследователя с изучаемым объектом) и теоретическое исследование (объект изучается опосредовано, в так называемом мысленном эксперименте). Напомним структуру последнего. Основными формами организации знания в его рамках являются: факт, теория, проблема (задача), гипотеза, программа. К методам теоретического исследования относятся: мыс- ленный эксперимент с идеализированными объектами, метод восхождения от абстрактного к конкретному, логический и исторический методы исследования, а также индуктивное обобщение [1, с. 266-268]. В «Энциклопедии эпистемологии и философии науки» под общей редакцией видного философа науки, И. Т. Касавина, под моделированием понимается «изучение некоторого объекта посредством наблюдений или эксперимента, проводимых с его моделью» [2, с. 529]. В том же источнике модель определяется как такой искусственный или естественный объект, обладающий «существенным, с точки зрения цели познания (проектирования), сходством с изучаемым объектом («прототипом») и может его имитировать в заданном отношении, будучи объектом исследования» [3, с. 529-530]. Определение математической модели, характерное для «чистой» математики, дано в справочнике по этой науке под редакцией Т. Корн и Г. Корн, где под математической моделью понимается «класс неопределяемых (абстрактных, символических) математических объектов таких, как числа или векторы, и отношения между этими объектами» [4, с. 368]. Во «Введении в математическое моделирование» под редак- 
цией специалиста в области механики сплошных сред П. В. Трусова даётся определение математической модели для «прикладной» математики: «любой оператор А, позволяющий по соответствующим значениям входных параметров $X$ установить выходные значения параметров Y объекта моделирования: $A: x \rightarrow y, x \in \Omega x, y \in \Omega y$, где $\Omega$ и и $\Omega$ - множества допустимых значений входных и выходных параметров для моделируемого объекта (числа, векторы, тензоры, функции, множества и т.п.)» [5, с. 35].

При этом важно сразу обозначить нашу методологическую позицию: опыт и естествознания, и социально-гуманитарного знания, особенного в современных их формах, не просто «говорит», а буквально "кричит», «взывает» о необходимости взаимодействия со знанием философским. Мы согласны, что «при анализе истории противоречивых попыток осмысления различными школами проблемы соотношения философии и частных наук ... (нельзя не - Т. Ш.) делать акцент на том подходе, который рассматривает их в единстве, утверждая их неразрывную сущностную взаимосвязь. В соответствии с традицией он может быть обозначен как диалектический» [6, с. 121]. Поэтому мы будем привлекать идеи философов разных эпох, включая античность, поскольку солидарны со следующим тезисом: «накопленный к концу второго десятилетия XXI века познавательный опыт человечества свидетельствует: по многим вопросам современной науки и философии люди 2-1 тысячелетия до н.э. (например, древние греки) выступают нашими современниками. И ими же останутся навсегда, поскольку они не только ставили, но и каждый по-своему жаждали решать «вечные» проблемы» [7, с. 9]. В том числе, добавим, и познавательные.

\section{1. История математического моделирования}

Отметим, что в научное понятие термин «модель» превратился «во второй половине XIX в. в работах Э. Бельтрами, Ф. Клейна и А. Пуанкаре, давших интерпретации неевклидовых геометрий в рамках евклидовой геометрии» $[8$, с. 6]; сегодня же это понятие «стало не только общенаучным, но и приобрело статус фундаментальной философской категории» [8, с. 6]. Академик А.А. Самарский, основоположник отечественного математического моделирования, математическое моделирование назвал «третьим методом» познания, которое сочетает в себе как теорию, так и эксперимент. Также, А.А. Самарский отмечает, что в настоящее время технические, социальные и другие сложные системы не могут быть исследованы с достаточной полнотой и точностью обычными теоретическими методами, а натурный эксперимент не всегда возможен, так как многие из этих систем существуют в «единственном экземпляре» [9, с. 7]. Например, принципиально неосуществимы эксперименты с прошлым какого-либо государства или народа («История не терпит сослагательного наклонения») [5, с. 21]. Более того, эксперименты в социально-гуманитарных науках морально проблематичны. Что же касается естественных наук, то и в них на сегодняшний день невозможно провести эксперименты по прямому исследованию, например, структуры звезд, далёких планет, и т.д. [5, с. 21]. Над экономическими объектами (предприятиями, банками, отраслями экономики и т.п.) натуральные эксперименты проводить очень дорого, а зачастую опасно, в связи с чем если они и возможны с технической точки зрения, то всё чаще признаются невозможными с точки зрения морали. Ведь неудачный экономический эксперимент может привести к большим потерям финансовых и материальных средств, повлиять на судьбы миллионов людей [10, с. 6].

В диссертационных работах (например, шифр специальности 05.01.01 «нженерная геометрия и компьютерная графика», шифр специальности 05.13.18 «Математическое моделирование, численные методы и комплексы программ») широко используются математические модели. Так, областью исследования для 05.01.01 являются построение геометрических моделей, непрерывное и дискретное геометрическое моделирование; для 05.13.18 - математическое моделирование, численные методы и комплексы программ. Но математическая модель и реальный процесс не совпадают. Математическая модель - это идеализированный объект, упрощенный. В «Энциклопедии эпистемологии и философии науки» указывается, что идеализированный объект суть «объект, составляющий объем понятия, полученного в результате акта идеализации. Примерами таких объектов в науке являются: материальная точка (объект, вся масса которого сосредоточена в одной точке), точечный электрический заряд (объект, электрический заряд которого сосредоточен в одной точке), идеальная жидкость (жидкость абсолютно несжимаемая и лишенная какойлибо вязкости), абсолютно черное тело (физическое тело, которое поглощает всю падающую на него лучистую энергию, ничего из нее, не отражая и не пропуская через себя) и подобные другие» [11, с. 261]. Поэтому при защите диссертационных работ с применением математических моделей необходимо экспериментальное подтверждение.

А.А. Самарский выделяет три этапа в истории математического моделирования [9, с. 6-7]. Первый этап начинается уже с самого начала возникновения естественных наук. Обозначенный автор в качестве примера математического моделирования на данном этапе приводит классическую механику точки И. Ньютона, с помощью которой можно описать движение любого математического объекта, размеры которого малы по сравнению с характерными расстояниями, проходимыми телом. Для более сложных расчетов механических систем применяются уравнения Лагранжа II рода $[12$, c. 4], являющиеся универсальным методом составле- 
ния дифференциальных уравнений движения материальных систем. В качестве примеров простых (оператор простой модели является алгебраическим выражением, отражающим функциональную зависимость выходных параметров Y от входных X) моделей можно привести многие законы физики: начиная с законов Ньютона, закон всемирного тяготения, закон Ома, закон Паскаля, закон сохранения заряда, закон Архимеда, закон сохранения импульса, а также все эмпирические, т.е. полученные из опыта, алгебраические зависимости между входными и выходными параметрами. Так, в теории ручной дуговой сварки для приближенных расчетов сварочный ток (один из основных параметров режима сварки) может быть определен через диаметр электрода и эмпирический коэффициент, зависящий от диаметра электрода [13, с. 310]. Модель, включающая системы дифференциальных и интегральных соотношений, уже не может быть отнесена к простым, так как для своего исследования требует применения довольно сложных математических методов.

Второй этап А.А. Самарский относит к концу 40-х началу 50-х годов XX века [9, с. 6-7]. Это связано с появлением первых компьютеров, которые выполняли хоть и несложные по нынешним меркам, но значительно упрощающие расчеты ученым. В это же время с помощью математического моделирования была выполнена национальная программа СССР и США по созданию ракетно-ядерного щита, которая не могла быть реализована традиционными методами. Ядерные взрывы, полеты ракет и спутников были вначале воспроизведены на компьютере с помощью математических моделей, а затем претворены на практике. Всё это способствовало развитию данной методологии, и теперь ни один крупномасштабный проект, будь то экономический, экологический, технологический, не обходится без предварительного моделирования [9, с. 6-7]. Простейшая модель роста $x^{*}=\mathrm{kx}$ предложена Томасом Мальтусом, видным представителем классической политической экономии Англии (для роста населения Земли) [14, с. 7]. Она ведет к экспоненциальному (т.е. очень быстрому) росту населения x с течением времени. Как считает академик В.И. Арнольд эта «жёсткая» модель применима, например, к развитию науки в 1700-1950 годах (измеряемому, скажем, числом научных статей). Продолжение экспоненциального роста науки в следующий век быстро привело бы к исчерпанию бумаги и чернил, причем число ученых должно было бы достичь половины населения земного шара [14, с. 7]. Ясно, что общество (во всех странах) не может этого допустить, и, следовательно, такой количественный рост учёных был приостановлен. При слишком больших х конкуренция за ресурсы (пищу, гранты и т.д.) приводит к уменьшению k, и «жёсткая» модель Т. Мальтуса должна быть заменена «мягкой» моделью $\dot{x}=k(\mathrm{x}) x$ с зависящим от на- селения коэффициентом размножения [14, с. 8].

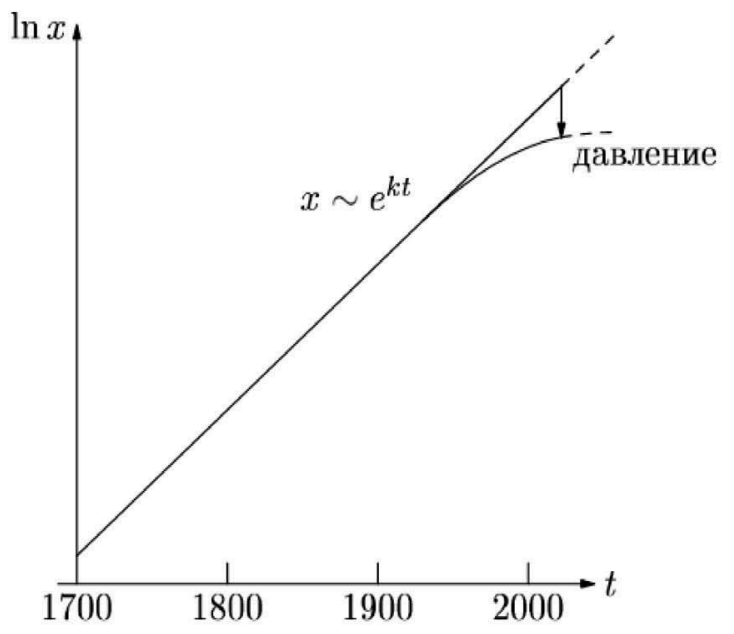

И наконец, третий этап в истории математического моделирования относится к настоящему времени [9, с. 6-7]. Сейчас, при переходе развитых стран к так называемому «информационному обществу», значение математического моделирования возрастает ещё более. Прогресс средств переработки, передачи и хранения информации отвечает мировым тенденциям, без владения информационными «ресурсами» нельзя и думать о решении проблем, стоящих перед мировым сообществом. Поэтому нужны надежные способы переработки информационного «сырья» в готовый «продукт», т.е. в точное знание [9, с. 7].

Развитие вычислительной техники породило новое направление в исследовании сложных процессов - имитационное моделирование. В учебном пособии для студентов, обучающихся по направлению «Бизнес-информатика», под редакцией доктора экономических наук Е.П. Бочарова, под имитационной системой понимается «совокупность модели, имитирующей изучаемое явление, и систем внешнего и внутреннего обеспечения. Для имитационной модели характерна имитация элементарных явлений, составляющих исследуемый процесс, с сохранением их логической структуры, последовательности протекания во времени, характера и состава информации о состояниях процесса» [10, с. 23]. История развития имитационного моделирования (ИМ) насчитывает уже более 50 лет. Но только в последние десятилетия в связи с появлением высокопроизводительных персональных компьютеров и соответствующих программ ИМ становится повседневным инструментом для разработчиков самых различных проектов - транспортных, промышленных, медицинских, военных и т.п. «Так, наличие имитационной модели и обоснование с её помощью выбранного варианта организации является обязательным в странах Европейского Союза в 
комплекте документов, подаваемых на рассмотрение для проектирования или модернизации нового производства либо технологического процесса. Им придается все большее значение и в директивных документах Правительства РФ по технологическому развитию» [10, с. 3]. «Многим специалистам термин «метод Монте-Карло» иногда представляется синонимом термина «имитационное моделирование», но понятие последнего более широкое, и метод Монте-Карло является важным, но далеко не единственным методическим компонентом имитационного моделирования» [10, с. 26]. В основе вычислений по методу Монте-Карло лежит случайный выбор чисел из заданного вероятностного распределения.

\section{2. Этапы построения математической модели}

Рассмотрев этапы становления математического моделирования как метода, перейдём к этапам применения последнего к делу решения тех или иных познавательных проблем. Методология математического моделирования в кратком виде выражена знаменитой триадой модель - алгоритм - программа, сформулированной А.А. Самарским [9, с. 7]. Сама постановка вопроса о математическом моделировании какого-либо объекта порождает четкий план действий. Его можно условно разбить на три этапа: модель - алгоритм - программа (см. схему):

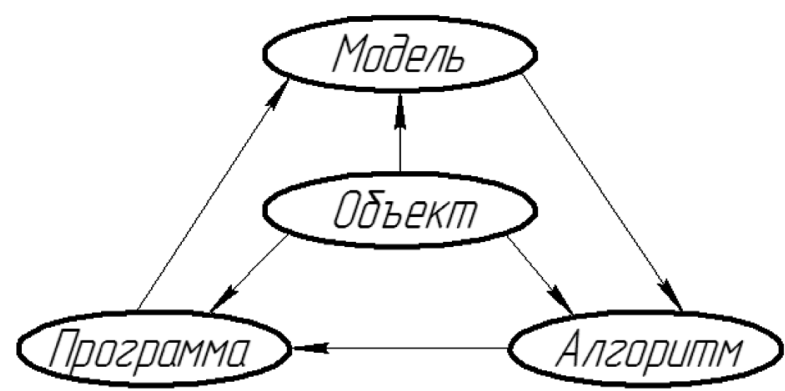

На первом этапе математического моделирования, как отмечает А.А. Самарский, «выбирается (или строится) «эквивалент» объекта, отражающий в математической форме важнейшие его свойства-законы, которым он подчиняется, связи, присущие составляющим его частям и т.Д., то есть математическая модель. Математическая модель (или ее фрагменты) исследуется теоретическими методами, что позволяет получить важные предварительные знания об объекте» [9, с. 7-8].

Любая модель нетождественна объекту-оригиналу и, значит, неполна, поскольку исследователь учитывал лишь важнейшие с его точки зрения факторы. Эту мысль хорошо выразили основоположники кибернетики и теории искусственного интеллекта Артуро Розенблют и Норберт Винер, сказав, что самой хорошей моделью кота является не теоретический объект, а другой кот, а ещё лучше - «тот же самый кот» [15]. Если результаты моделирования удовлетворяют исследователя и могут служить основой для прогнозирования поведения или свойств исследуемого объекта, то говорят модель адекватна (от лат. adaequatus - приравненный) объекту. Специалисты, известные работой над клеточными автоматами, Томмазо Тоффоли и Норман Марголус высказываются о моделях, способных предсказывать, получать новые знания об исследуемом объекте: «в науке мало пользы от моделей, которые рабски подчиняются нашим желаниям. Мы хотим иметь модели, которые дерзят нам; модели, которые имеют свой собственный ум. Мы хотим получать от моделей больше, чем в них вложили» $[16$, с. 152]. П.В. Трусов отмечает, что модели, не обладающие определенной «предсказательностью», едва ли могут считаться удовлетворительными [5, с. 20].

Согласно П.В. Трусову «предметная (физическая) модель отображает внешние, наглядные свойства объекта в реальном, материальном объекте-копии. Предметные модели обеспечивают наибольшую наглядность по сравнению с информационными моделями. Их ещё называют натурными, так как они реализуют физическое подобие объекта: муляж, макет, собственно модель. Эти модели часто используют на занятиях в учебных учреждениях, при проведении опытов и исследований в специализированных лабораториях в институтах. Например, глобус - учебная модель для изучения Земли. Опытная модель самолета - для испытаний в аэродинамической трубе и т.Д.» $[5$, с. 25].

К математическим моделям известный специалист по теории познания, методологии науки, доктор философских наук В.А. Штофф относит различные кибернетические модели, главным отличием которых от других моделей является наличие «каналов обратной связи, по которым поступает информация от исполнительного органа в управляющий, благодаря чему поддерживается определенная направленность поведения системы при изменяющихся внешних условиях» $[17$, с. 25]. Существенной особенностью данных моделей от физических и аналоговых моделей является то, что «отношение кибернетических моделей к моделируемым объектам основано главным образом на сходстве, одинаковости поведения и функций сложных систем, могущих различаться во всех других отношениях (изофункционализм)» [17, с. 25]. «Забегая вперёд», скажем, что это очевидным образом порождает проблему: где та граница, до которой математическая модель может отличаться от физического объекта?

Второй этап - выбор (или разработка) алгоритма для реализации модели на компьютере [9, с. 8]. Модель представляется в форме, удобной для применения численных методов, определяется последовательность вы- 
числительных и логических операций, которые нужно произвести, чтобы найти искомые величины с заданной точностью. Вычислительные алгоритмы должны не искажать основные свойства модели и, следовательно, исходного объекта, быть экономичными и адаптирующимися к особенностям решаемых задач и используемых компьютеров.

На третьем этапе создаются программы, «переводящие» модель и алгоритм на доступный компьютеру язык $[9$, с. 8]. К ним также предъявляются требования экономичности и адаптивности. Их можно назвать «электронным» эквивалентом изучаемого объекта, уже пригодным для непосредственного испытания на «экспериментальной установке» - компьютере.

Создав рассматриваемую триаду, исследователь получает в руки универсальный, гибкий и недорогой инструмент, который вначале отлаживается, тестируется в «пробных» вычислительных экспериментах. После того как адекватность (достаточное соответствие) триады исходному объекту удостоверена, с моделью проводятся разнообразные и подробные «опыты», дающие все требуемые качественные и количественные свойства и характеристики объекта. Процесс моделирования сопровождается улучшением и уточнением, по мере необходимости, всех звеньев триады [9, с. 8].

Будучи методологией, математическое моделирование не подменяет собой математику, физику, биологию и другие научные дисциплины, не конкурирует с ними. Наоборот, трудно переоценить его синтезирующую роль.

\section{3. Онтологический статус математических моделей}

Поиск ответа на поставленный вопрос заставляет вначале рассмотреть проблему статуса математических объектов в целом. Т.е. мы заходим в пределы философии математики - это область исследования, объектом которой являются «основания математического знания, место математики в системе знания, онтологический статус математических объектов, методы математики» [18, с 216-218].

Как отмечает омский философ М.Г. Федотова, обозначенный статус математических объектов уже в античности определялся двумя способами, один из которых восходит к Платону, а второй - к Аристотелю [19, с. 201-202]. Если мы принадлежим к первой из этих традиций, то вынуждены признать, что «математические объекты изначально имели онтологический статус, отличный от бытия вещей, реально существуя в мире идей» [19, с. 201]. Тогда математическое моделирование для нас даже более достоверно, чем натурный эксперимент. По этому поводу шведско-американский космолог и астрофизик Макс Тегмарк высказывается: «поделюсь с вами своей (на пер- вый взгляд сумасшедшей) идеей: наш физический мир не только описывается математикой, он и есть математика, делающая нас самосознающими частями гигантского математического объекта» [20, с. 10]. Схожим образом и английский физик и математик Роджер Пенроуз пишет, что «многие физики и математики предпочли бы считать физический мир порождением «вневременного» математического мира идей» [21, с. 11].

Если же мы принадлежим к «линии философствования, идущей от Аристотеля, математические объекты являются абстракциями, высшей формой отвлечения от свойств конкретных вещей, имеющими своего рода «прототипы» в физической, материальной реальности» [19, с. 201-202]. В этом случае материальные объекты не первичные онтологические сущности, типа платоновских эйдосов, а результат абстракции.

Рассмотрение этого пункта завершим указанием на то, что возможно и иное решение вопроса статуса математических объектов, нежели солидаризация с одной из рассмотренных традиций, восходящих к Аристоклу и Стагириту. Например, В.О. Бернацкий и П.Г. Макухин, на основе разрабатываемой ими методологии диалектики бытия и действительности, утверждают, что, с одной стороны солидаризуются «с реализмом Платона в том, что объекты математики не есть некие чисто субъективные конструкции ..., (с другой же стороны, не могут - Т.Ш.) согласиться, что мир эйдосов это и есть Бытие: указанный мир ... (явился - Т.Ш.) одной из первых интуиций Действительности» [22, с. 69].

\section{4. Гносеологическая оченка математического моделирования}

Основываясь материалистической, а точнее - диалектико-материалистической позиции, рассмотрим идеи представителя последней, В.А. Штоффа. Этот видный советский специалист в области философских проблем построения научных моделей писал, что последние несут в себе элементы истины, причём последняя характеризуется как объективная (в противоположность субъективной) и относительная (в противоположность субъективной). Во-первых, модели зависят от познающего субъекта и его психических способностей (анализ и синтез, отвлечение, идеализация, творческое воображение, фантазия и т.п.). Во-вторых, они (модели) существуют лишь как психические образы в сознании отдельных индивидов. Однако, несмотря на эти два момента - в чём нельзя не согласиться с В.А. Штоффом - имеется объективное содержание, которое не зависит от человека и которое, являясь объективной истиной, определяет научный познавательный характер моделей [17, с. 69]. Признание объективной истинности научных моделей является необходимым условием научного исследования. «Модель является выражением относительной ис- 
тинности, так как каждая модель является временной, преходящей, отражающей лишь исторически определенную ступень проникновения познания в объективную структуру и закономерности развития мира» [17, с. 241].О модельном эксперименте как критерии истинности теории В.А. Штофф отмечает: «успех эксперимента с моделью есть косвенное, вероятностное доказательство теории применительно к объекту» $[17$, с. 245]. Однако прямые эксперименты не везде и не всегда практически возможны и технически осуществимы, как и говорилось нами ранее. «Поэтому моделирование в подобных условиях является весьма важным способом практической проверки, испытания и косвенного доказательства истинности соответствующих теорий и гипотез» [17, с. 244].

Солидаризуясь с этими тезисами, добавим к ним ту мысль, которую считаем принципиально важной. На процесс построения математической модели влияет научная картина мира в целом, и содержащиеся в ней конкретные теории, в частности. Что, однако же, зачастую не осознаётся самими учёными. Например, в XIX веке метод моделирования применялся в рамках механистической картины мира, которая абсолютизировала механическое движение. Максвелл при построении своей электромагнитной теории широко пользовался механическими моделями, он убежден что эти модели отражают существующий в природе способ взаимодействия между материальными частицами, который в принципе является механическим [17, с. 43].

Также часто игнорируется, что в теоретических объектах содержатся черты, которых нет у реальных объектов. В реальности не бывает материальных точек, абсолютного твердого тела, идеального газа.

\section{Зак^ючение}

Таким образом, сегодня математическое моделирование является важным инструментом исследователя в различных отраслях науки. При этом мы не должны видеть в моделях прямое отражение физического объекта в духе линейного онтологизма; в частности, ещё и оттого, что на процесс их построения влияет научная картина мира или какие-то её фрагменты. Тем не менее, математические модели, построенные в соответствие с рассмотренными правилами, содержат истинное знание; причём нельзя забывать, что речь об относительной истине, т. е. в целом верном, но неполном и неточном знании, содержащем элементы заблуждения. В то же время в принципе невозможно построить модель чего бы то ни было, способную сообщить нам абсолютно истину об изучаемом объекте.

Автор благодарит научного руководителя статьи к.филос.н., дочента кафедры «История, философия и социальные коммуникации» ОмГТУ Макухина П. Г

\section{ЛИТЕРАТУРА}

1. Кулиш М.В. Уровни научного знания // Общие проблемы философии науки: словарь для аспирантов и соискателей / Сост. и общ. ред. Н.В. Бряник; отВ. ред. О.Н. Дьячкова. - Екатеринбург: Изд-во Урал. ун-та, 2007. - С. 266-268.

2. Караваев Э.Ф. Моделирование // Энциклопедия эпистемологии и философии науки. - М.: «Канон» РООИ «Реабилитация», 2009. - С. 529.

3. Растянников А.В. Модель // Энциклопедия эпистемологии и философии науки. - М.: «Канон» РООИ «Реабилитация», 2009. - С. 529-530.

4. Корн Г., Корн Т. Справочник по математике (для научных работников и инженеров). - М.: Наука, 1978. - 832 с.

5. Введение в математическое моделирование. Под ред. Трусова П.В. - М.: Логос, 2005. - 336 с.

6. Макухин П.Г. Куточнению истории диалектического подхода к взаимодействию философии и науки: А. Рей о статусе философии и её функциях в отношении науки // Социально-гуманитарное знание: история и проблемы современности: монография. - St. Louis, Missouri, USA: PublishingHouseScienceandlnn ovationCenter, 2015. - Pp. 121-135.

7. Бернацкий В.О., Макухин П.Г. 0 предвосхищении диалектики бытия и действительности в античных размышлениях о природе времени: досократики // Россия и мировые тенденции развития. Материалы Всероссийской научно-практической конференции с международным участием. (0мск, 13-15 мая 2019 г.). - Омск: Изд-во ОмГТУ, 2019. - С. 8-15.

8. Вечтомов Е.М. Гносеологический статус математических моделей // Вестник ВятГУ. - 2011. - № 4. - С. 6-12.

9. Самарский А.А., Михайлов А.П. Математическое моделирование: Идеи. Методы. Примеры. - М.: Физматлит, 2001. - 320 c.

10. Имитационное моделирование экономических процессов: учебное пособие для студентов, обучающихся по направлению подготовки 080500.62 «Бизнес-информатика» / авт.-сост. Е.П. Бочаров, О.Н. Алексенцева / Саратовский социально-экономический институт (филиал) ФГБОУ ВПО «РЭУ им. Г.В. Плеханова». - Саратов: Саратовский социально-экономический институт (филиал) ФГБОУ ВПО «РЭУ им. Г.В. Плеханова», 2014. - 160 с.

11. Субботин А.Л. Идеализированный объект // Энциклопедия эпистемологии и философии науки. - М.: «Канон» РООИ «Реабилитация», 2009. - С. 261.

12. Артемов И.И. Применение уравнений Лагранжа второго рода для решения задач динамики: метод. указания/ И.И. Артемов, В.Н. Плешаков, А.А. Елисеева. - Краснодар: КубГАУ, 2013. - 30 с.

13. Технология металлов и сварка. Учебник для вузов. Под ред. П.И. Полухина. - М.: Высшая школа, 1977. - 464 с.

14. Арнольд В.И. «Жёсткие» и «мягкие» математические модели. - М.: МЦНМ0, 2000. - 32 с.

15. Розенблют А., Винер Н. Роль моделей в науке // Модели в науке и технике. - Л.: Наука. Ленинградское отделение, 1984. - С. 171-175. 
16. Тоффоли Т., Марголус Н. Машины клеточных автоматов. - М.: Мир, 1991. - 280 с.

17. Штофф В.А. Моделирование и философия. - М. - Л.: Наука, 1966. - 302 с.

18. Гутнер Г.Б. Философия математики // Новая философская энциклопедия: в 4 т. Т. 4. - 2-е изд. - М.: Мысль, 2010. - С. 216-218.

19. История и философия науки: учеб. пособие / [М.Г. Федотова и др.]; под общ. ред. М.Г. Федотовой. - Омск: Изд-во ОмГТУ, 2018. 372 с.

20. Тегмарк М. Наша математическая вселенная. В поисках фундаментальной природы реальности. - Москва: Издательство ACT: CORPUS, 2017. - 592 c.

21. Пенроуз Р., Шимони А., Картрайт Н., Хокинг С. Большое, малое и человеческий разум. - М.: Мир, 2004. - 191 с.

22. Макухин П.Г. Фундаментальные физические постоянные как инструменты и продукты становления «Действительности» (опыт нового методологического подхода к проблеме «тонкой настройки Вселенной») // Контекст и рефлексия: философия о мире и человеке. - 2020. - Том 9. № 2A. - С. 57-72. DOI: $10.34670 /$ AR.2020.68.61.006.

( Ш Шевелева Татьяна Анатольевна (tatyana0781@mal.ru).

Журнал «Современная наука: актуальные проблемы теории и практики»

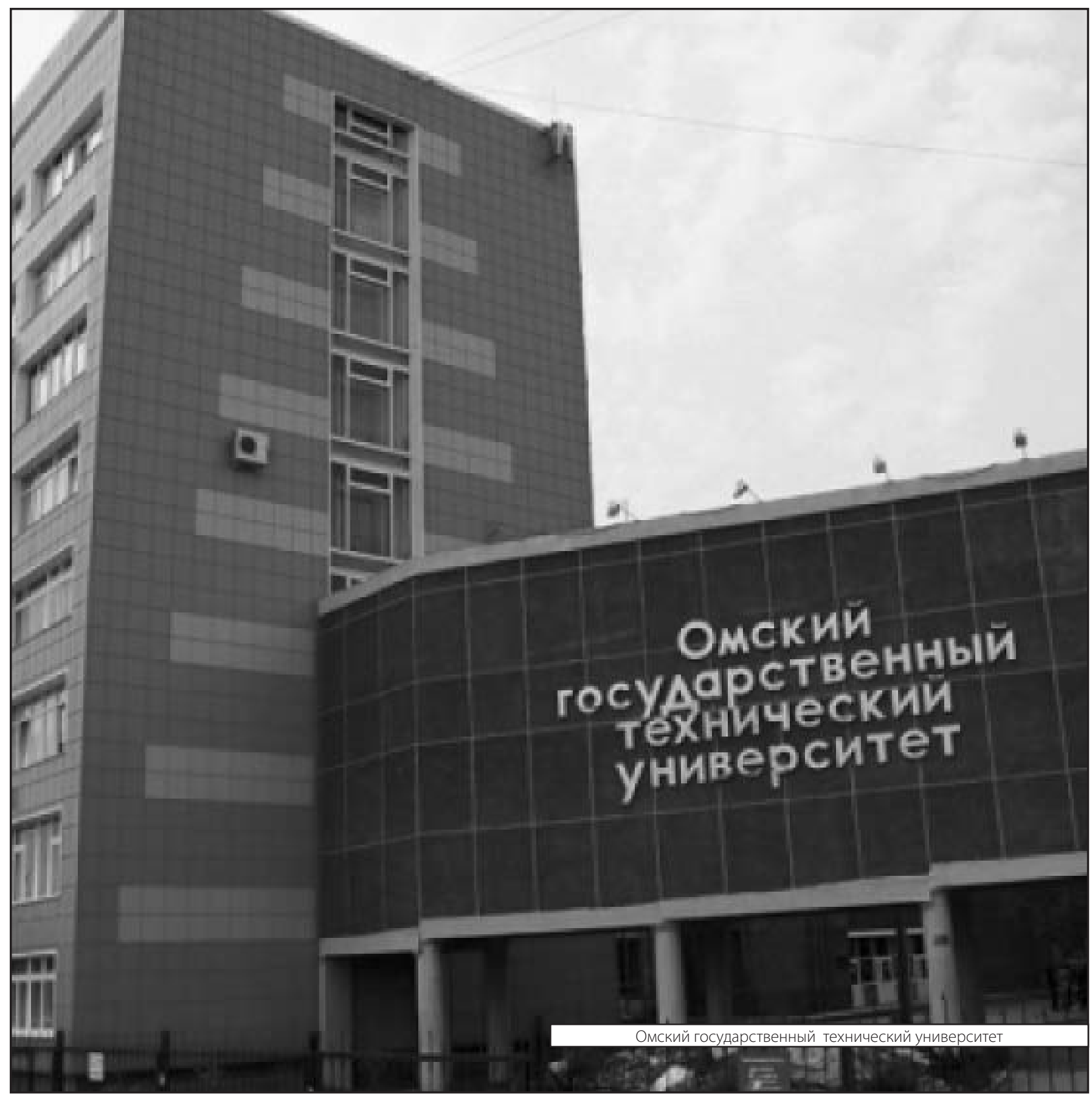

